\title{
Joint research on a real-time information network using $X$ band MP radar for advanced storm-water management
}

\author{
R. Matsuoka, H. Couchiwa \& M. Onishi \\ Japan Institute of Wastewater Engineering and Technology, Japan
}

\begin{abstract}
A regional heavy rainfall event, known as 'a Guerilla storm', causes severe damage to the limited area and frequently occurs these days. X band MP radar is capable of observing weather conditions with higher resolution and frequency compared with $\mathrm{C}$ band radar, so that it can observe the motion of regional rainfall in detail with high precision. A real-time information network (RTN) is a system that collects and provides information on rainfall, water levels/flow rates, storm-water pump operation, etc. in real time. The introduction of a RTN is thought to facilitate understanding of current conditions through the visualization of water levels/flow rates in main lines, and also enables the efficient use of existing facilities to be planned, such as the optimization of pump operation. This research aimed to verify the accuracy of RTN using X band MP radar information. In this research, rainfall predictions were conducted for up to 60 minutes in advance by a movement prediction method using rainfall data observed and transmitted by an X band MP radar network. As a result, the accuracy of the prediction by the RTN using X band MP radar is verified at a certain level of accuracy, and it is considered to be practical if the prediction time is 30 minutes or so.

Keywords: flood control, real time, information network.
\end{abstract}

\section{Objective}

A regional heavy rainfall event, known as 'a Guerilla storm', causes severe damage to a limited area and frequently occurs these days. X band MP radar is capable of observing weather conditions with higher resolution and frequency compared with $\mathrm{C}$ band radar (hereinafter referred to as Japan Meteorological 
Agency radar), so that it can observe the motion of regional rainfall in detail with high precision. Therefore, by introducing X band MP radar data in a "real-time rain information network" [1], it is expected that the accuracy of the actual value and the predictive value of rainfall and water level of the pipe line can be improved $[2,3]$.

As a countermeasure to heavy rain that has occurred in recent years, the Japanese government began the operation of the $\mathrm{X}$ band MP radar network (hereafter XRAIN), so that it would be possible to obtain the data of X band MP radar.

This study was conducted for the purposes of the establishment of technology related to the rainfall prediction method using X band MP radar and a real-time information network (RTN) utilizing its information, and confirmed the accuracy of the RTN.

\section{Researchers and period}

\subsection{Researchers}

- Japan Weather Association.

- METAWATER Co., Ltd.

- Japan Institute of Wastewater Engineering and Technology.

\subsection{Period}

From April 2012 to March 2013 (one year).

\section{Results}

\subsection{Rainfall prediction}

Accuracy evaluation was conducted by comparing both predictive and the actual values of the $\mathrm{X}$ band MP radar. The target to evaluate the accuracy was $\mathrm{S}$ drainage district in A City which is able to be observed by two $\mathrm{X}$ band MP radars. ('A City' is one of the cities in Japan, and 'S drainage district' is one of the flood-prone areas.)

\subsubsection{Rainfall prediction method using $X$ band MP radar data}

Out of the observation range of X band MP radar, the supplement was conducted using Japan Meteorological Agency radar (JMA radar). A comparison of the rainfall distribution map of $\mathrm{X}$ band MP radar with JMA radar is shown in Figure 1.

In this way, the heavy rain area was observed by the X band MP radar but the data were missing in the observational range, the shielded area and the radio wave dissipating area (displayed in gray in Figure 1). The predictive value was created using initial value data which were complemented with JMA radar. 


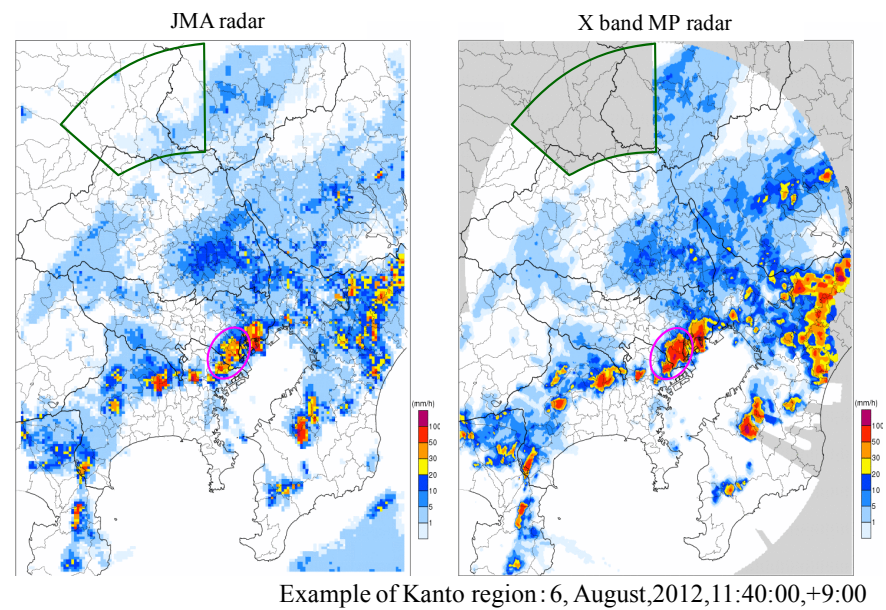

Figure 1: Comparison with JMA radar (left) and X band radar (right).

\subsubsection{Accuracy verification of actual and predictive value}

A flow of the accuracy verification of actual and predictive value in this study is shown in Figure 2. The scope of accuracy verification is in A City, and regarding $\mathrm{X}$ band MP radar, the predictive value and the measured value were compared by calculating the basin average rainfall of the target drainage districts. At this time, the scores were calculated by extracting only heavy rain, and the accuracy was evaluated at the time of heavy rain.

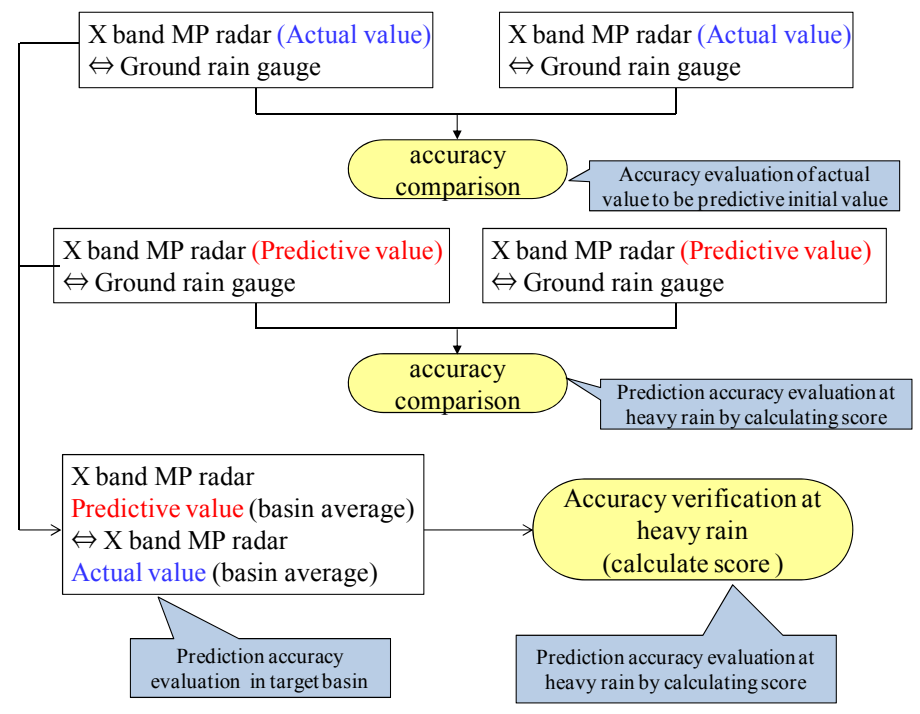

Figure 2: Flow of accuracy verification of the predictive value and the actual value. 
The accuracy verification was conducted by extracting intended rainfall cases. The rainfall example was extracted at the point in time when it fell at a rate of $10 \mathrm{~mm}$ or more per hour in the four points of AMeDAS in A City, and the 6 hours before and after that. The rain gauge to be used for accuracy verification had a total of 25 points; 4 points of AMeDAS used to extract the example and 21 points of the rain gauge data which were owned by A City.

The accuracy verification of the predictive value was evaluated by the basin average rainfall, in conjunction with the evaluation by the ground rain gauge. The intended basin is two basins: $\mathrm{K}$ drainage district and $\mathrm{S}$ drainage district (' $\mathrm{K}$ drainage district' is one of the flood-prone areas in A City). The results of accuracy verification were evaluated by four accuracy evaluation indicators: the regression coefficient, the correlation coefficient, the total rainfall ratio, and root mean square error (RMSE; see Table 1).

The correlation coefficient is an index representing the similarity value, RMSE is an index representing the magnitude of the error, the regression coefficient and the total rainfall ratio is an indicator of the quantitative magnitude of the value.

Table 1: List of the accuracy evaluation indicators.

\begin{tabular}{|c|c|c|c|}
\hline & calculation method & content & way of looking at evaluation \\
\hline $\begin{array}{l}\text { regression } \\
\text { coefficient } a\end{array}$ & $\begin{array}{l}\text { The value of a formula; } \mathrm{y}=\mathrm{ax} . \\
\text { Calculated by } \\
\text { the right formula } \\
\text { using correlation } a=\sqrt{\frac{\sum_{i=1}^{N}\left(y_{i}\right)^{2}}{\sum_{i=1}^{N}\left(x_{i}\right)^{2}}} \\
\text { recurrence } \\
\text { OfType II . }\end{array}$ & $\begin{array}{l}\text { Index to evaluate the } \\
\text { quantitative degree of } \\
\text { coincidence } \\
\text { : more than } 0\end{array}$ & $\begin{array}{l}\text { If greater than } 1, \text { then more } \\
\text { than ground rainfall. } \\
\text { If smaller than } 1, \text { then less } \\
\text { than ground rainfall. }\end{array}$ \\
\hline $\begin{array}{l}\text { correlation } \\
\text { coefficient } r\end{array}$ & $\begin{array}{l}\text { Calculated by the following } \\
\text { formula. } \\
\qquad r=\frac{\sum_{i=1}^{N}\left(y_{i}-\bar{y}\right)\left(x_{i}-\bar{x}\right)}{\sqrt{\sum_{i=1}^{N}\left(y_{i}-\bar{y}\right)^{2}} \sqrt{\sum_{i=1}^{N}\left(x_{i}-\bar{x}\right)^{2}}}\end{array}$ & $\begin{array}{l}\text { Index to evaluate } \\
\text { the similarity } \\
\text { (correlation) } \\
\text { :from - } 1 \text { to } 1\end{array}$ & $\begin{array}{l}\text { If close to } 1, \text { then correlation } \\
\text { with ground rainfall is } \\
\text { strong.(There is a correlation) } \\
\text { If close to } 0 \text {, then correlation } \\
\text { with ground rainfall is weak. } \\
\text { (There is no correlation) }\end{array}$ \\
\hline $\begin{array}{l}\text { Total rainfall } \\
\text { ratio } s\end{array}$ & $\begin{array}{l}\text { Calculated by } \\
\text { the right formula } \\
\text { using total rainfall. }\end{array} \quad s=\frac{\sum_{i=1}^{N} y_{i}}{\sum_{i=1}^{N} x_{i}}$ & $\begin{array}{l}\text { Index to evaluate } \\
\text { the small and large } \\
: \text { more than } 0\end{array}$ & $\begin{array}{l}\text { If greater than } 1, \text { then more } \\
\text { than ground rainfall. } \\
\text { If greater than } 1, \text { then less } \\
\text { than ground rainfall. }\end{array}$ \\
\hline $\begin{array}{l}\text { RMSE } \\
\text { (Root Mean } \\
\text { Square Error) }\end{array}$ & $\begin{array}{l}\text { Calculated by the following } \\
\text { formula using error (radar } \\
\text { rainfall-grand rainfall). } \\
\qquad R M S E=\sqrt{\frac{1}{N} \sum_{i=1}^{N}\left(y_{i}-x_{i}\right)^{2}}\end{array}$ & $\begin{array}{l}\text { Index to evaluate the } \\
\text { magnitude of the error } \\
\text { (absolute value) } \\
\text { :more than } 0\end{array}$ & $\begin{array}{l}\text { If close to } 0 \text {, then the } \\
\text { difference between the ground } \\
\text { rainfall is smaller. } \\
\text { (Value can be considered as in } \\
\mathrm{mm} \text { ) }\end{array}$ \\
\hline$y_{i}$ & $\begin{array}{l}\text { ground rainfall(mm) } \\
\text { radar rainfall }(\mathrm{mm}) \\
\text { total sample count }\end{array}$ & $\begin{array}{l}\text { nd rainfall average }(\mathrm{mm}) \\
\text { r rainfall average }(\mathrm{mm})\end{array}$ & \\
\hline
\end{tabular}

\subsubsection{Accuracy verification of actual value}

The accuracy of the actual value of $\mathrm{X}$ band MP radar was verified by comparing the ground rainfall. 
The result is shown in Figure 3. In this figure the distance from the radar site is also close, to within about $30 \mathrm{~km}$, although the trend is slightly larger in quantity with comparison from ground rainfall was observed, the result was high accuracy that the correlation coefficient of 10 -min rainfall was 0.9 or more.

Regarding the actual value of JMA radar (10-min and 60-min rainfall), we show the results of performing verification with the ground rainfall in Figure 3. Looking at the correlation coefficient, it is equal to or lower than 0.6 at 10 -min rainfall and we obtain a better result in the accuracy of X band MP radar. Regarding JMA radar, the trend of slightly lower quantity was observed.

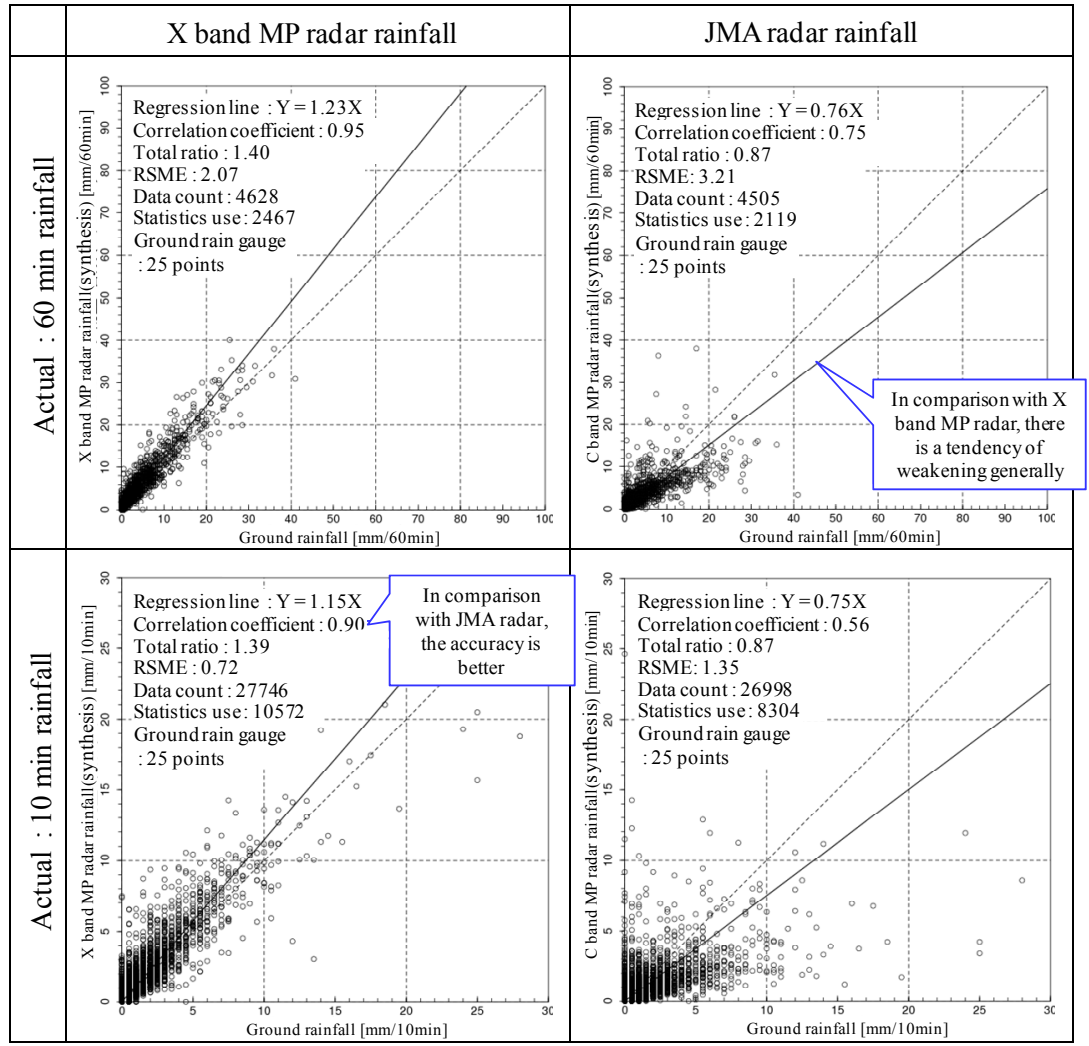

Figure 3: Results of accuracy verification of the actual value of $\mathrm{X}$ band MP radar and JMA radar (upper: 60-min rainfall; lower: 10-min rainfall).

The difference between heavy rain and light rain was confirmed from a comparison of the actual value of the light-rain case (29 November) and heavyrain case (23 October).

The results of accuracy verification of each case are shown in Figure 4. According to this, there was no major difference in the accuracy evaluation index 
in the light-rain case and heavy-rain case. In addition, the accuracy was verified by dividing all of the cases into heavy rain and or light rain. However, there was no tendency that difference of accuracy which caused by the intensity of the rain.

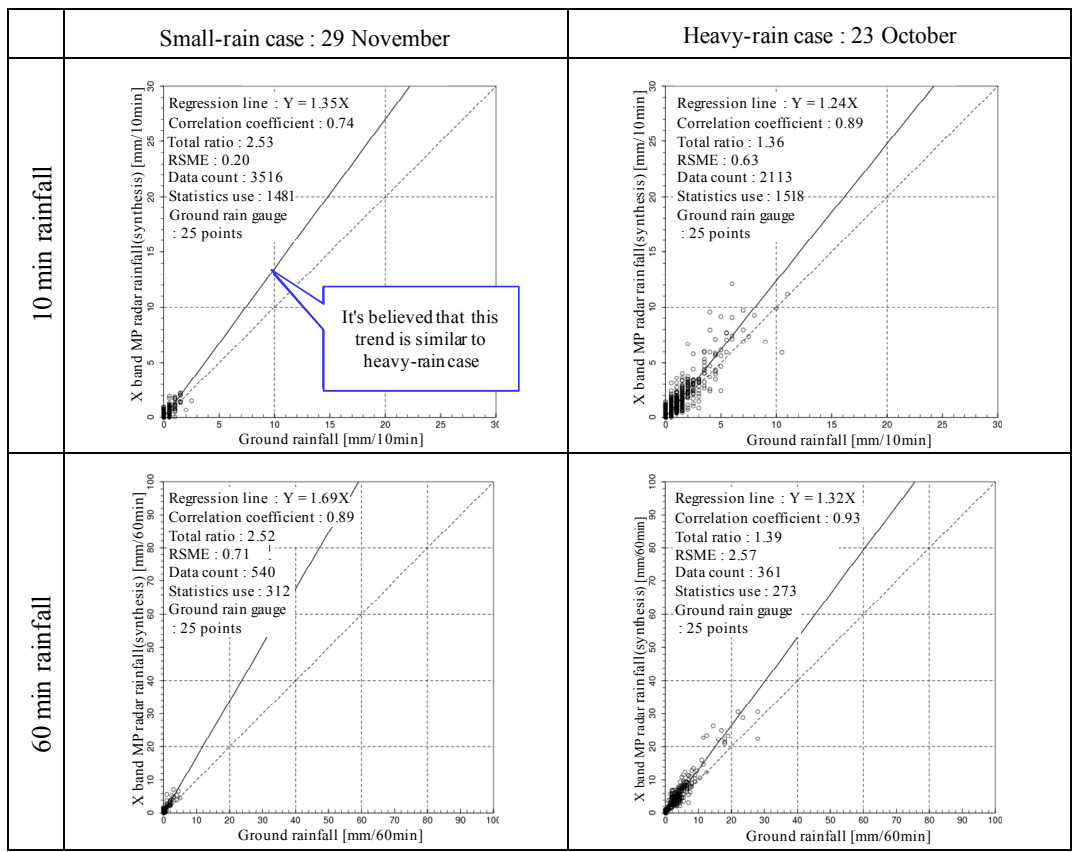

Figure 4: Comparison with scatter plots of the heavy-rain and light-rain cases (upper: 10-min rainfall; lower: 60-min rainfall).

\subsubsection{Accuracy verification of the prediction value}

The accuracy of the prediction value of the X band MP radar was verified by comparing the ground rainfall. The verification was conducted with 10-min rainfall and 60 -min rainfall.

Regarding the JMA radar predictive value, the accuracy verification for a comparison of the ground rainfall was conducted and compared with the $\mathrm{X}$ band MP radar predictive value.

First, regarding the 60-min rainfall, the result of the verification accuracy of JMA radar predictive value with the $\mathrm{X}$ band MP radar predictive value was compared. The result is shown Figure 5 (for comparison, it also shows the result with the actual value).

According to this, in comparison with the correlation coefficient, the prediction accuracy was better with X band MP radar than JMA radar.

In addition, in quantitative terms, the predictive value of JMA the radar took relatively small value compared to ground rainfall.

Next, regarding 10-min rainfall predictive value, the accuracy verification of up to 10 -min rainfall from 60 -min rainfall was conducted every 10 minutes. The 


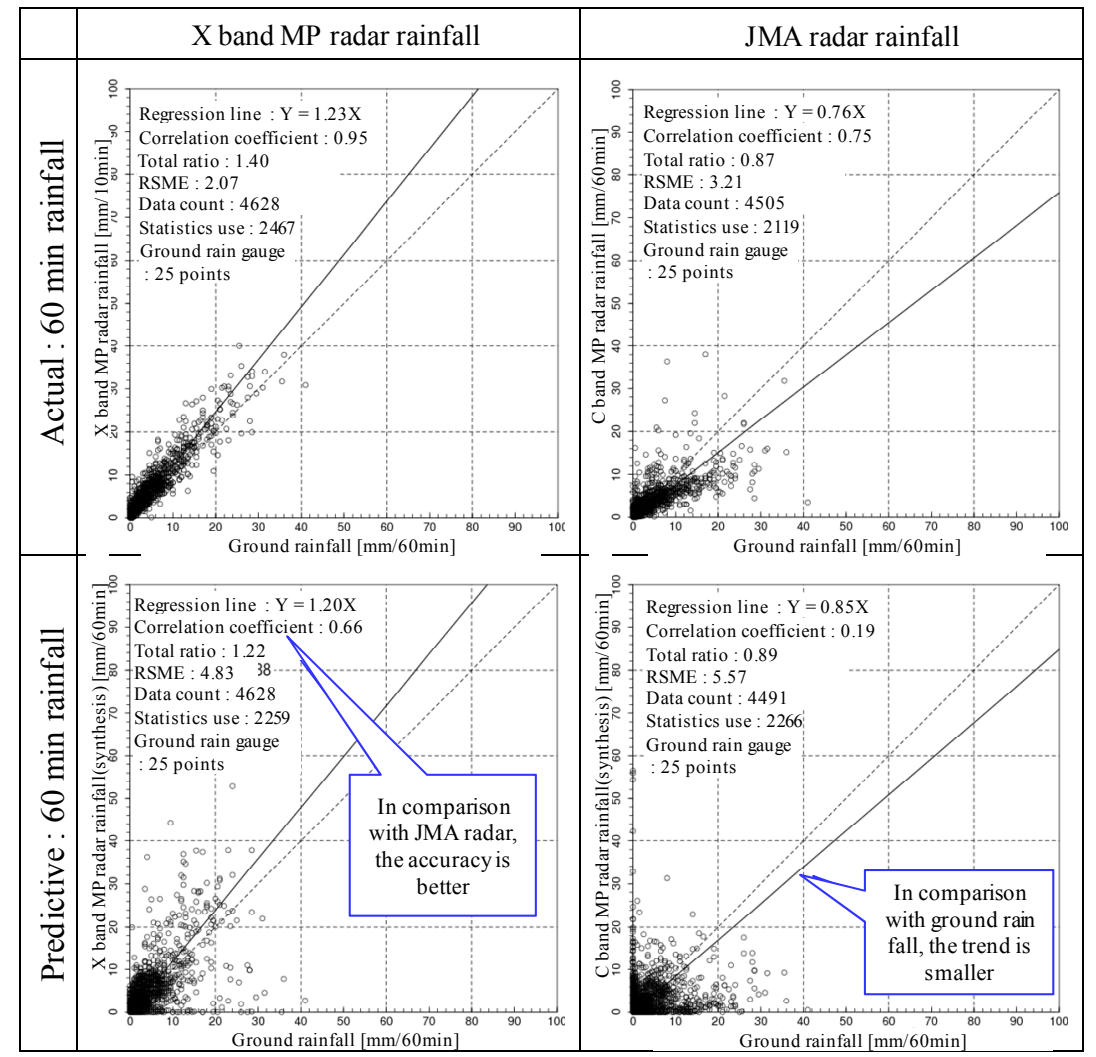

Figure 5: Accuracy verification result of the predictive value of $\mathrm{X}$ band MP radar and JMA radar (upper: actual value; lower: predictive value).

verification result of the predictive value, from $10 \mathrm{~min}$ to $30 \mathrm{~min}$ is shown in Figure 6, and from $40 \mathrm{~min}$ to $60 \mathrm{~min}$ is shown in Figure 7.

According to this, regarding both radars, it was proved that we have high accuracy in cases where the prediction time is short, and the accuracy is lower in the case when the prediction time is longer. However, due to the influence of the accuracy of the initial value, the accuracy was reduced considerably in the 10min JMA radar, and the correlation was less than or equal to zero beyond $50 \mathrm{~min}$.

Looking quantitatively, JMA radar has become too small in the stage of initial value, and this trend was continued even if the prediction time has progressed. The JMA radar predictive value (labeled JMA in the graph) and X band MP radar predictive value (labeled XRAIN in the graph) were compared by the accuracy evaluation index which was calculated. The result which was organized the accuracy evaluation index of predictive every 10 minutes is shown in Table 2, and the results which were compared by graph are shown in Figure 8.

When looking at the correlation coefficient, $\mathrm{X}$ band MP radar achieved higher accuracy results than the JMA radar for the entire prediction time. 
The prediction of the JMA radar excluded from the comparison, because the correlation coefficient became 0 or less in 50 and $60 \mathrm{~min}$.

In terms of the total rainfall ratio and regression coefficient as a quantitative trend, it tends to predict the results slightly more in X band MP radar, and with JMA radar it is clear that there is a tendency to predict sparingly.

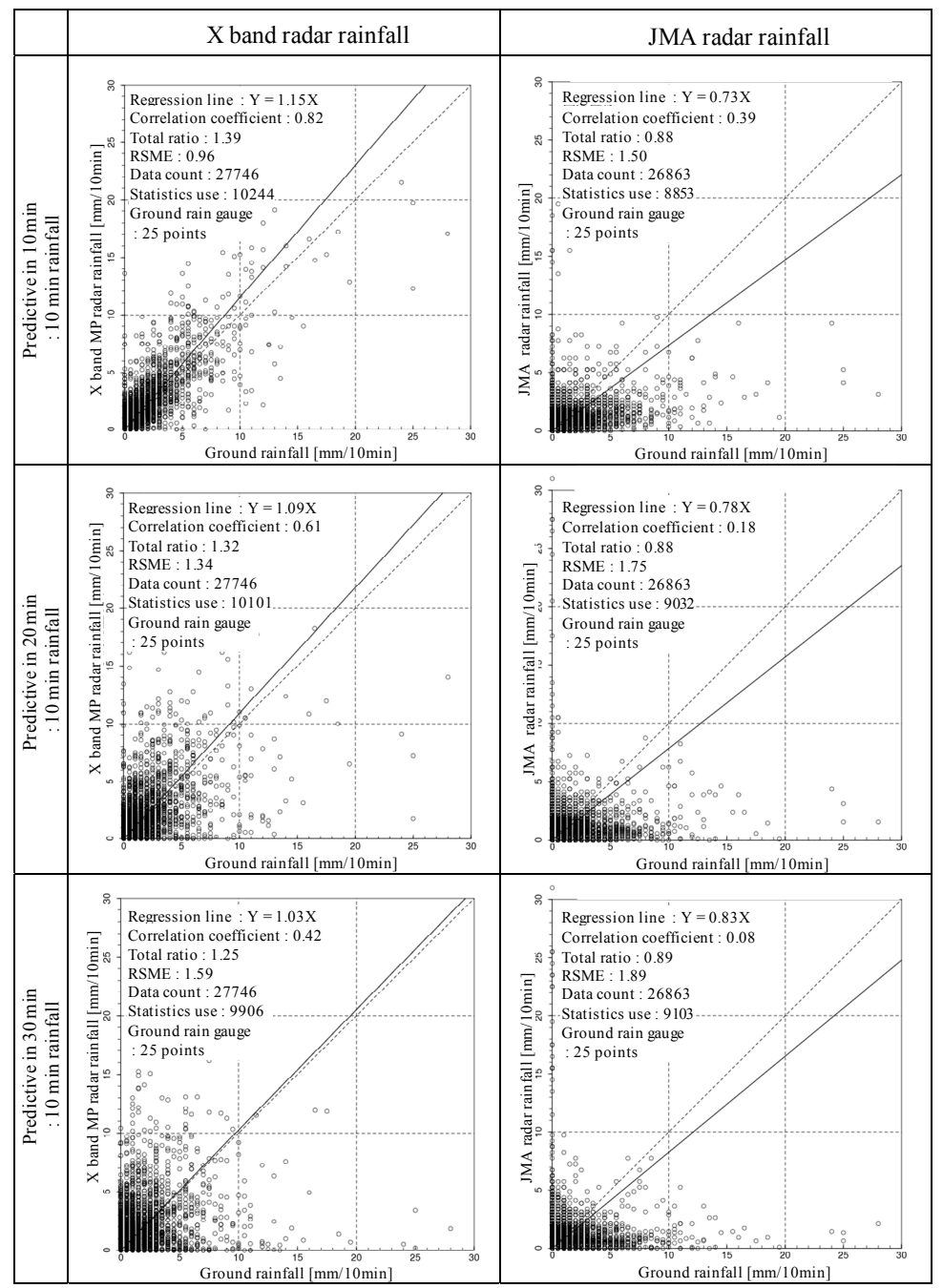

Figure 6: Accuracy verification result of the predictive value of the JMA radar and $\mathrm{X}$ band MP radar; 10-min rainfall (top: 10-min prediction; middle: 20 -min prediction; bottom: 30 -min prediction). 


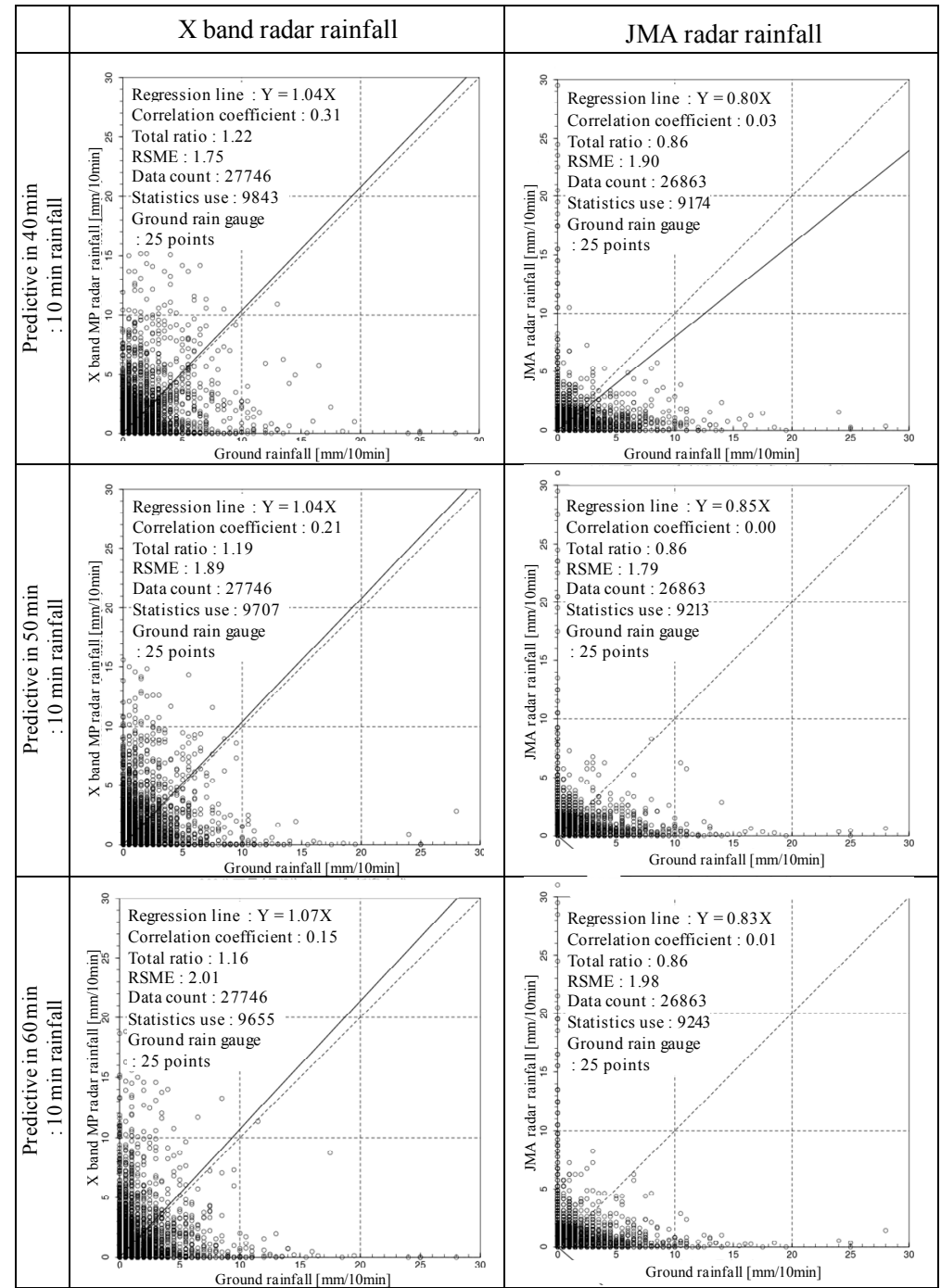

Figure 7: Accuracy verification result of the predictive value of the JMA radar and $\mathrm{X}$ band MP radar: 10-min rainfall (top: 40-min prediction; middle: 50 -min prediction; bottom: 60 -min prediction). 

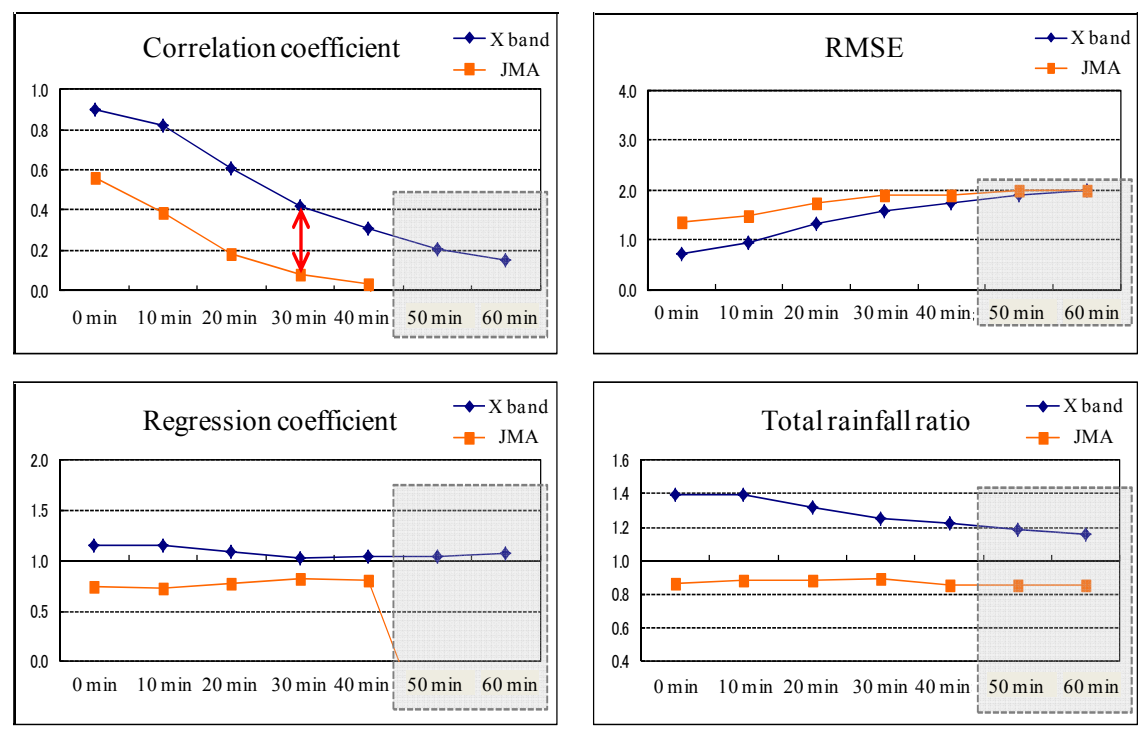

Figure 8: Comparison of verification accuracy index of up to $60 \mathrm{~min}$.

\subsubsection{Accuracy verification of the predictive value by average basin rainfall}

Regarding X band MP radar predictive value, the basin average rainfall were verified. The actual value of the basin average rainfall was created from the actual value of $\mathrm{X}$ band MP radar. At this time, the basin average rainfall was calculated by averaging the mesh rainfall $(1$ mesh is about $250 \mathrm{~m} \times 250 \mathrm{~m})$ in each basin of $\mathrm{S}$ drainage district (catchment area: $8.65 \mathrm{~km}^{2}$ ) and $\mathrm{K}$ drainage district (catchment area: $0.80 \mathrm{~km}^{2}$ ).

The accuracy of $\mathrm{X}$ band MP radar predictive values was verified by the basin average rainfall in the actual value of the $\mathrm{X}$ band MP radar. The result is shown in Figure 9. According to this, both basins had similar trend that correlation coefficient is about 0.7 , so that it is considered to be a relatively good accuracy.

In addition, the verification of the predictive value of the basin average rainfall was conducted in each basin every 10 minutes until 60 minute. We extracted the accuracy evaluation index from these results and it is summarized in the graph in Figure 10 and Table 2.

According to these results, the correlation coefficient is more than 0.5 in 30 minutes in both basins, and there is tendency of being slightly better than the precision of point rainfall. The total rainfall ratio was less than 1.0. It is believed that this precipitation that develops more on land in practice, and there is a tendency that the prediction is calculated slightly smaller. 

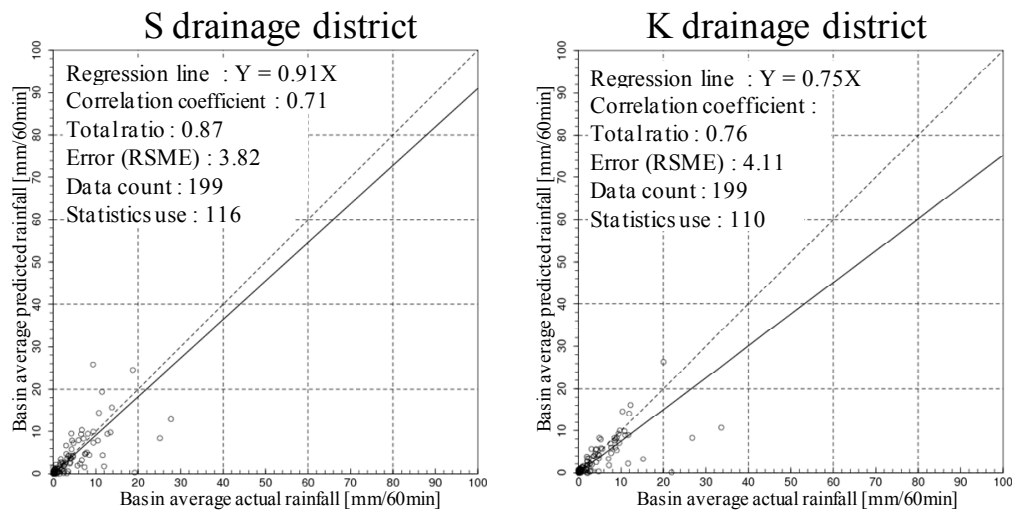

Figure 9: Accuracy verification of the predictive value by the average basin rainfall: 60 -min rainfall (left: $\mathrm{S}$ drainage district; right: $\mathrm{K}$ drainage district).

Table 2: $\quad$ List of accuracy evaluation index in 60 minutes (left: S drainage district; right: $\mathrm{K}$ drainage district).

\begin{tabular}{|l|r|r|r|r|}
\hline S drainage & $\begin{array}{c}\text { Correlation } \\
\text { coefficient }\end{array}$ & $\begin{array}{c}\text { Regression } \\
\text { coefficient }\end{array}$ & RMSE & $\begin{array}{c}\text { Total } \\
\text { rainfall } \\
\text { ratio }\end{array}$ \\
\hline in $10 \mathrm{~min}$ & 0.91 & 0.99 & 0.55 & 0.98 \\
\hline in $20 \mathrm{~min}$ & 0.75 & 0.94 & 0.89 & 0.93 \\
\hline in $30 \mathrm{~min}$ & 0.53 & 0.91 & 1.20 & 0.88 \\
\hline in $40 \mathrm{~min}$ & 0.35 & 0.90 & 1.40 & 0.83 \\
\hline in 50 min & 0.28 & 0.85 & 1.45 & 0.79 \\
\hline in $60 \mathrm{~min}$ & 0.25 & 0.84 & 1.46 & 0.75 \\
\hline
\end{tabular}

\begin{tabular}{|l|r|r|r|r|}
\hline K drainage & $\begin{array}{c}\text { Correlation } \\
\text { coefficient }\end{array}$ & $\begin{array}{c}\text { Regression } \\
\text { coefficient }\end{array}$ & RMSE & $\begin{array}{c}\text { Total } \\
\text { rainfall } \\
\text { ratio }\end{array}$ \\
\hline in 10 min & 0.90 & 0.99 & 0.70 & 0.97 \\
\hline in $20 \mathrm{~min}$ & 0.75 & 0.82 & 1.05 & 0.88 \\
\hline in 30 min & 0.56 & 0.82 & 1.36 & 0.85 \\
\hline in 40 min & 0.34 & 0.80 & 1.63 & 0.79 \\
\hline in 50 min & 0.22 & 0.76 & 1.74 & 0.74 \\
\hline in 60 min & 0.20 & 0.82 & 1.53 & 0.74 \\
\hline
\end{tabular}
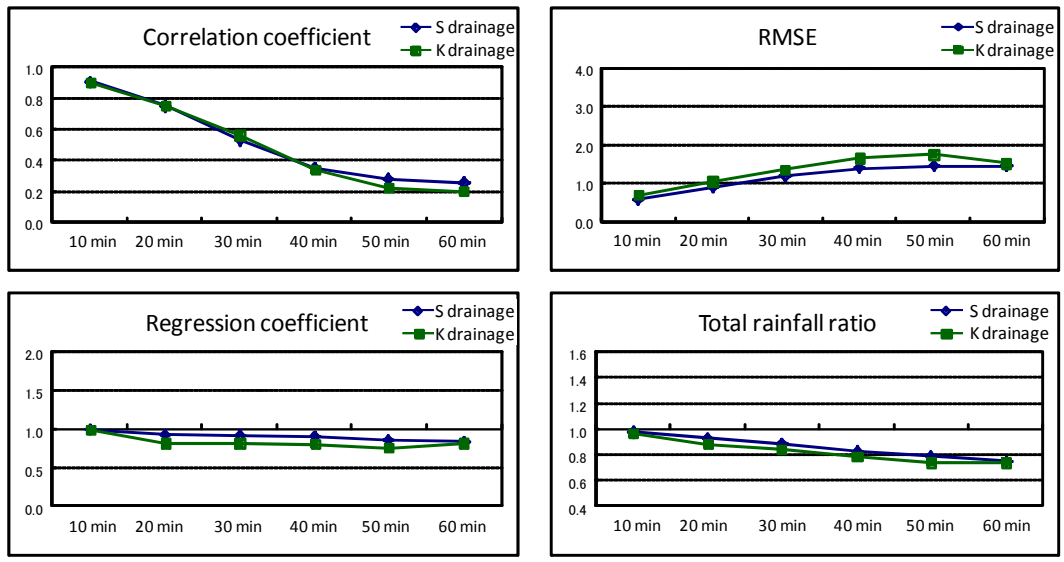

Figure 10: Comparison of verification accuracy index in 60 minutes: every 10 minutes (basin average rainfall predictive value). 


\subsection{Prediction of storm-water runoff in pipe line}

The accuracy of the prediction analysis was confirmed by introducing the predictive rainfall into an analysis model which confirmed the accuracy. As initially status analysis is based on the each pump operating record and the rainfall records, the prediction was analyzed by predictive rainfall at passage afterwards.

The accuracy confirmation of predictive analysis was confirmed by comparing the predictive analysis value from the observed value of pipeline water level and the pump well water level of each pump station, etc. Prediction analysis accuracy of the water level was the result which can be judged as being substantially similar to the observed values as a whole. Moreover, the prediction analysis accuracy tends to be higher in average rain than in light rain. In the case of rainfall prediction by $\mathrm{X}$ band MP radar, it is considered that the accuracy is better when comparing the predictive water level because rainfall prediction accuracy is higher. In this time, the accuracy of predictive analysis about two levels of rainfall were confirmed, so it is necessary to check the accuracy of prediction analysis for heavy rain and plurality rainfall.

\section{Summary}

In this study, there is a certain level of the accuracy if the entire drainage district, and so the accuracy of the prediction using X band MP radar is considered to be practical in the case of prediction by about 30 minutes.

Regarding the prediction of the pipe line, because it is to be the prediction reflected past rainfall with taking into account the reaching time, it is considered that the accuracy moreover is improved. It is believed that it is possible to predict with high accuracy for when using $\mathrm{X}$ band MP radar for the sewer pipe in rainwater runoff analysis, and it is expected that the use will spread by improving the prediction accuracy in the future.

\section{References}

[1] Ishikawa Tadao (ed.), Riarutaimu Usui Jouhou Nettowa-ku Gijutsushiryou, pp.7, Japan Institute of Wastewater Engineering and Technology, 2011.

[2] Manabu Onishi, Riarutaimu Usui Jouhou Nettowa-ku wo mochiita usui koudokannri ni kansuru kyoudoukennkyu, Dai 50 kai Gesuidokenkyu Happyoukai Kouenshu, pp. 223, 2013.

[3] Manabu Onishi, X band MP redar wo katsuyoushita Riarutaimu Usui Jouhou Nettowa-ku ni kansuru kyoudoukennkyu, 2012 nendo Gesuido Shingijutukennkyuujo Nenpou, pp. 19-24, 2013. 